\title{
An unusual case of dengue shock syndrome complicated by ilio-femoral deep vein thrombosis; a case report
}

\author{
K. M. I. U. Ranasinghe 1* $^{*}$, D. Dissanayaka², K. Thirumavalavan ${ }^{2}$ and M. Seneviratne ${ }^{2}$
}

\begin{abstract}
Background: Dengue fever is a hemorrhagic fever caused by flaviviruses. Hemorrhagic manifestations are well known to be associated with dengue fever, though the thrombotic events are only seldom reported. Underlying pathophysiology of thrombotic events is multifactorial and the management is challenging due to associated thrombocytopenia and bleeding tendency. We report a case of dengue shock syndrome with severe thrombocytopenia complicated by ilio-femoral deep vein thrombosis.

Case presentation: A 16 year old boy presented with dengue fever. He had dengue shock syndrome after entering the critical phase on the fifth day of the illness. With the recovery from the critical phase he developed deep vein thrombosis involving right external iliac, common femoral and superficial femoral veins. There were no provocative factors other than dengue fever itself. His platelet count was $12,000 / \mu \mathrm{l}$ at the time of diagnosis with deep vein thrombosis. Anticoagulation was started with intravenous unfractionated heparin 500 IU/hour while closely being observed for bleeding complications. $1000 \mathrm{IU} /$ hour dose was commenced with the recovery of the platelet count above 50,000/ $\mathrm{\mu l}$. Thrombophilia screening was negative and he was discharged on warfarin. Venous duplex done after 6 weeks showed normal lower limb venous flow and warfarin was omitted after three months.
\end{abstract}

Conclusions: With dengue fever, complications like deep vein thrombosis can be easily missed given its rarity and that the major concern is on hemorrhagic complications. Management is challenging due to associated thrombocytopenia and hemorrhagic complications.

Keywords: Dengue, Dengue shock syndrome, Deep vein thrombosis, Thrombocytopenia

\section{Background}

Dengue fever is a hemorrhagic fever caused by flaviviruses. Five antigenically related but distinct serovars have been identified, even though the strain 5 is not known to be associated with human infections so far. Bites of infected female mosquitoes Aedes aegypti and Aedes albopictus result in virus transmission. Incubation period is between 4 and 10 days [1]. It is endemic in many countries, highest in parts of Asia and South America.

\footnotetext{
* Correspondence: indrachaparanasinghe@gmail.com

${ }^{1}$ Registrar in Medicine, National Hospital of Sri Lanka, Colombo, Sri Lanka Full list of author information is available at the end of the article
}

In Sri Lanka, a total of 55,894 dengue cases and 74 deaths due to dengue fever have been reported within the year of 2019 as at October 18th. This is a significant increase of the disease burden in contrast to 2018 where only 58 dengue deaths were reported during the whole year [2]. Not confining to Sri Lanka, incidence of the disease has dramatically risen worldwide during the past few years making dengue fever, a major public health concern. WHO has declared that about half of the world population is now at risk of the disease [3].

Dengue causes a wide spectrum of diseases ranging from asymptomatic infection to severe flu-like symptoms. The World Health Organization classifies dengue

(C) The Author(s). 2020 Open Access This article is licensed under a Creative Commons Attribution 4.0 International License, which permits use, sharing, adaptation, distribution and reproduction in any medium or format, as long as you give appropriate credit to the original author(s) and the source, provide a link to the Creative Commons licence, and indicate if changes were made. The images or other third party material in this article are included in the article's Creative Commons licence, unless indicated otherwise in a credit line to the material. If material is not included in the article's Creative Commons licence and your intended use is not permitted by statutory regulation or exceeds the permitted use, you will need to obtain permission directly from the copyright holder. To view a copy of this licence, visit http://creativecommons.org/licenses/by/4.0/ The Creative Commons Public Domain Dedication waiver (http://creativecommons.org/publicdomain/zero/1.0/) applies to the data made available in this article, unless otherwise stated in a credit line to the data. 
into two major categories: dengue (with / without warning signs) and severe dengue. Severe dengue is characterized by plasma leaking, fluid accumulation, respiratory distress, severe bleeding, organ impairment and metabolic abnormalities [3, 4].

Hemorrhagic manifestations are well known to be associated with dengue. Thrombotic events complicating acute dengue illness are seldom reported and only case reports are found in literature [5-7]. There is a descriptive study done in Brazil where five patients were reported having deep vein thrombosis. All of them had dengue fever without evidence of plasma leakage. Three other reported cases, including two from Sri Lanka had deep vein thrombotic events following recovery from the initial infection, but none of them had severe thrombocytopenia $(<20,000 / \mu \mathrm{l})$ during the time of occurrence of the thrombotic event $[5,6,8,9]$.

We report a case of a patient with dengue shock syndrome, who developed ilio-femoral deep vein thrombosis during the critical phase, despite severe thrombocytopenia of $12,000 / \mu \mathrm{l}$.

\section{Case presentation}

A 16 year old Sri Lankan boy presented to the National Hospital of Sri Lanka, with a 4 day history of high grade fever, arthralgia, myalgia and headache. He was obese with a Body Mass Index of $28 \mathrm{~kg} / \mathrm{m}^{2} . \mathrm{NS}_{1}$ antigen positivity confirmed the diagnosis of dengue fever. On the fifth day of the illness he went into the critical phase as evidenced by fluid in the hepato-renal pouch in bedside ultrasound scan. His platelet count was $52,000 / \mu \mathrm{l}$ at the time of entering the critical phase. Other hemodynamic parameters were stable and the urine output was within the desired range. By the 18th hour of the critical phase he went into compensated shock. Initial crystalloid bolus was given according to the national guideline for the management of dengue.

His hemodynamic parameters improved after 2 hours with a blood pressure of $100 / 75 \mathrm{mmHg}$ and the urine output more than $0.5 \mathrm{ml} / \mathrm{kg} / \mathrm{hr}$. Packed Cell Volume (PCV) dropped to $46 \%$ from $51 \%$. His baseline PCV on admission was $40 \%$. He again went into compensated shock the next hour requiring another two crystalloid boluses. After maintaining hemodynamic parameters stable for 2 hours, he went into uncompensated shock and PCV was $46 \%$. As the PCV rise could not explain the shock by fluid leakage alone, immediate red cell transfusion was arranged. He was given another two boluses of dextran consecutively followed by another $5 \mathrm{ml} /$ $\mathrm{kg}$ red cell transfusion as hemodynamics did not improve. He responded gradually to the above management. During this period, other causes for poor response to fluid resuscitation, including ABCS, were excluded. Bedside ultrasound scan did not show any intra- abdominal bleeding. He did not have any other overt bleeding manifestation.

His lowest platelet count was $7000 / \mu \mathrm{l}$, and that was on the first day of the critical phase. By the end of the second day of the critical phase it rose to $12,000 / \mu$ l. On the third day after entering the critical phase, he complained of right sided leg swelling and pain. Examination revealed grossly swollen erythematous right lower limb with increased warmth and tenderness. Early convalescence rash was apparent. Clinical suspicion of deep vein thrombosis was confirmed by lower limb duplex scan, which showed deep vein thrombosis involving right external iliac, common femoral and superficial femoral veins.

As the latest platelet count by the time of diagnosis of deep vein thrombosis was $12,000 / \mu \mathrm{l}$, we were in a therapeutic dilemma. Thromboembolism deterrent (TED) stockings were applied to the unaffected limb and until anticoagulation right lower limb was kept immobile. Hematology opinion was taken, after which anticoagulation with unfractionated heparin (UFH) was decided. Coagulation studies, PT/INR, APTT were within the normal range. While awaiting repeat full blood count, intravenous UFH $500 \mathrm{IU} /$ hour was started. We observed him closely for bleeding. Platelet count had risen up to $58,000 / \mu \mathrm{l}$ in the next full blood count, after which UFH dose was increased to $1000 \mathrm{IU} /$ hour. APTT was $48 \mathrm{~s}$ and $54 \mathrm{~s}$ at the 6th hour and the 12th hour of UFH respectively. Warfarin was commenced the next day and therapeutic range (INR 2-3) was achieved by the sixth day of the diagnosis of DVT.

As thrombotic events are rare in severe dengue illness, we looked for other thrombophilia conditions. He did not have any significant past history to suggest thrombotic events. Thrombophilia screening which included anticardiolipin antibodies, anti beta 2 glycoprotein, protein $C$ and $S$ levels and prothrombin gene mutation was negative. Above investigations were arranged before starting UFH, as anticoagulation would affect the results otherwise. The patient was discharged after 12 days of hospitalization. He did not have any other complication of dengue fever apart from transient liver transaminitis which resolved before discharging. He was reviewed after 6 weeks from the onset of DVT and venous duplex showed recanalization of the right sided lower limb deep veins with a normal venous flow. Warfarin was omitted at the end of 3 months.

\section{Discussion and conclusions}

Although hemorrhagic manifestations are well known to occur with dengue fever, only a few cases complicated with thrombotic events are reported. Up to now the largest number of reported cases is from Brazil. Ninety-two serologically confirmed patients were studied from 
January 2011 to March 2011, where five patients were given the diagnosis as having large vessel thrombosis representing $5.4 \%$ of all dengue patients. Thrombotic events reported were, two cases of ilio-femoral deep vein thrombosis, two cases of pulmonary embolism and a case of mesenteric vein thrombosis. All these events occurred within the first 5 days of admission, and the lowest platelet count reported was $37,000 / \mathrm{microl}$. None of the affected patients were classified as having dengue shock syndrome or dengue hemorrhagic fever [5]. Three other reported cases of deep vein thrombotic events were found in the literature. All those patients developed deep vein thrombotic events after the recovery from the acute illness and the recovery of the platelet count $[8,9]$. Another two cases of cerebral venous thrombosis were reported where dehydration associated with the illness was thought to be the causative factor [10,11].

An arterial thrombotic event manifested as an ischemic stroke was reported in India in a patient with dengue fever. He did not have underlying conventional risk factors for an ischemic stroke. In addition to transient hypercoagulability of dengue fever, meningovasculitis was considered responsible for this occurrence [12].

Thrombus formation and propagation are caused by abnormalities of the blood flow, vascular endothelium and blood clotting components, collectively known as Virchow's triad. In dengue hemorrhagic fever and shock syndrome due to plasma leakage, there is a significant hemoconcentration manifested by high PCV. During the initial period of shock our patient had PCV of $51 \%$, whereas his baseline was $40 \%$ depicting significant hemoconcentration. However this amount of PCV rise by about $20 \%$ is not uncommon with severe dengue, and it does not cause thrombosis usually. Notably hypovolemic shock in our patient was not entirely due to plasma leakage, as the PCV did not rise as would be seen in case of shock only due to plasma leakage. He required red cell transfusions as well for the hemodynamic stability. The exact point of bleeding could not be identified, however concealed hemorrhages are well known to occur with dengue fever which could have been the case with our patient as well.

Factors associated with thrombosis in dengue fever are not well described in the literature. Myriad of factors including enhanced complement activation, cytokine storm due to antibody-dependent enhancement of infection and enhanced immune complex formation may increase thrombotic events in these patients. In the early course of severe dengue fever, loss of endothelial nonthrombogenic protective factors has been identified [13, 14]. Infected endothelial cells are known to express thrombomodulin facilitating coagulation [15]. Hemoconcentration during the critical phase, immobility during the hospital stay and usage of colloids in the management of shock will also enhance thrombogenecity in patients with dengue hemorrhagic fever.

A reduction in the level of activated protein $C$ is seen in association with dengue viral infection probably due to down regulation of thrombomodulin-thrombinprotein $\mathrm{C}$ complex formation. In addition, low plasma concentration of protein $\mathrm{S}$, tissue factor inhibitor and antithrombin III has been reported with severe dengue fever, though it is not associated with clinical thrombosis $[14,16,17]$. The levels of these factors are inversely proportional to the severity of shock and are likely caused by capillary leakage [14]. In addition, plasma concentrations of Plasminogen activator inhibitor type-I (PAI-1) are seen elevated with dengue infection [13].

An imbalance in the vWF-ADAMTS-13 system has been observed recently in association with dengue infection complicating the understanding of the pathogenesis of coagulopathy. In patients with severe illness low levels of ADAMTS-13 and high levels of elongated active vWF were discovered. Thus unregulated vWF due to low levels of ADAMTS13, leads to the platelet glycoprotein receptor Ib exposure to another platelet, facilitating platelet aggregation and the generation of platelet rich micro thrombi $[18,19]$.

As described above a constellation of factors may contribute to the development of thrombosis in a patient with dengue fever, rarely leading to major thrombotic events. This case describes a rare complication of dengue fever, deep vein thrombosis. Pulmonary embolism may cause or worsen hemodynamic instability complicating the condition further. Thus physicians' awareness about this rare complication is of paramount importance in managing unusually complicated cases of dengue infection with fluid unresponsiveness.

\section{Abbreviations}

ABCS: Acidosis, bleeding, calcium, sugar; ADAMTS-13: A disintegrin and metalloproteinase with thrombospondin type 1 motif, member 13: APTT: Activated partial thromboplastin time; BMI: Body mass index; DVT: Deep vein thrombosis; PCV: Packed cell volume; PT/INR: Prothrombin time, international normalized ratio; TED: Thromboembolism-deterrent; UFH: Unfractionated heparin; VVF: Von Willebrand factor

\section{Authors' contributions}

IR, KT and DD managed the patient during the critical phase. IR and MS liaised with the hematology team in management of deep vein thrombosis. IR wrote the first draft. DD and MS revised it. KT did the final revision including the language corrections. All authors have read and approved the final manuscript.

\section{Funding}

In managing the patient or in writing the case report we did not receive any funding.

Availability of data and materials

All necessary data and material are provided.

Ethics approval and consent to participate Not applicable. 


\section{Consent for publication}

Informed written consent for publishing the patient's personal and clinical details alongside any identifying images was taken from the father for this scientific publication.

\section{Competing interests}

The authors declare that they do not have any competing interests.

\section{Author details}

'Registrar in Medicine, National Hospital of Sri Lanka, Colombo, Sri Lanka.

2Physician, National Hospital of Sri Lanka, Colombo, Sri Lanka.

Received: 10 February 2020 Accepted: 29 April 2020

Published online: 12 May 2020

\section{References}

1. World Health O. Dengue: Guidelines for Diagnosis, Treatment, Prevention and Control. Dengue: Guidelines for Diagnosis, Treatment, Prevention and Control. Geneva: World Health Organization; 2009. p. 14-15.

2. Dengue alarm: 55,894 cases, 74 deaths so far. https://www.news.lk/news/ political-current-affairs/item/27840-dengue-alarm-55-894-cases-74-deaths-sofar. Accessed 20 Dec 2019

3. Dengue and severe dengue. https://www.who.int/news-room/fact-sheets/ detail/dengue-and-severe-dengue. Accessed 20 Dec 2019.

4. Biswas AP, Devgan G, Singla V, Murthy P, Dhariwal P, Sen A, Baruah PKK. Indian national guidelines for clinical management of dengue fever. 2015; 113:196-206.

5. da Costa PS, Ribeiro GM, Junior CS, da Costa Campos L. Severe thrombotic events associated with dengue fever, Brazil. Am J Trop Med Hyg. 2012;87(4): 741-2. https://doi.org/10.4269/ajtmh.2012.11-0692.

6. Agarwal A, Sharma S, Airun M. Life-threatening thrombo-embolic events in a case of dengue hemorrhagic fever. J Assoc Physicians India. 2016;64(8):87-89.

7. Roy A, Chaudhuri JA, Chakraborty S. Deep vein thrombosis associated with dengue fever. Indian Pediatr. 2013;50(11):1053. https://doi.org/10.1007/s13312-013-0269-8.

8. Samarasekara K, Munasinghe J. Dengue shock syndrome complicated with acute liver failure and kidney injury, infective endocarditis, and deep vein thrombosis: a case report. J Med Case Rep. 2018 Dec;12(1):321. https://doi. org/10.1186/s13256-018-1862-1.

9. Dissanayake NUA. Life threatening thromboembolic event following Dengue hemorrhagic fever. Sri Lankan J Cardiol. 2019;1(2):69-72.

10. Tilara M, Shah AN, Negi S, Dadhania J. A case of cerebral venous thrombosis in the patient with dengue. Int J Sci Res Publ. 2014;4(8):1-1.

11. Vasanthi N, Vairamon PM, Gowtham T, Das AK. Unusual presentation of dengue fever-cerebral venous thrombosis. J Clin Diagn Res. 2015;9(6):OD09. https://doi.org/10.7860/JCDR/2015/13132.6068

12. Manappallil RG. Ischemic stroke following Denque fever: a case report. Asian J Med Sci. 2016;7(2):107-108. doi.org/https:/doi.org/10.3126/ajms.v7i2.13340.

13. Mairuhu AT, Mac Gillavry MR, Setiati TE, Soemantri A, Ten Cate H, Brandjes DP, van Gorp EC. Is clinical outcome of dengue-virus infections influenced by coagulation and fibrinolysis? A critical review of the evidence. Lancet Infect Dis. 2003;3(1):33-41. https://doi.org/10.1016/s1473-3099(03)00487-0.

14. Wills BA, Oragui EE, Stephens AC, Daramola OA, Dung NM, Loan HT, Chau NV, Chambers M, Stepniewska K, Farrar JJ, Levin M. Coagulation abnormalities in dengue hemorrhagic fever: serial investigations in 167 Vietnamese children with dengue shock syndrome. Clin Infect Dis. 2002; 35(3):277-85. https://doi.org/10.1086/341410

15. Cabello-Gutiérrez C, Manjarrez-Zavala ME, Huerta-Zepeda A, Cime-Castillo J, Monroy-Martínez V, Biruete-Correa B, Ruiz-Ordaz BH. Modification of the cytoprotective protein C pathway during Dengue virus infection of human endothelial vascular cells. Thromb Haemost. 2009;101(05):916-28. doi.org. https://doi.org/10.1160/TH08-04-0271.

16. Turpie AG, Chin BS, Lip GY. Venous thromboembolism: pathophysiology, clinical features, and prevention. BMJ. 2002;325(7369):887-90. https://doi. org/10.1136/bmj.325.7369.887.

17. Yang KD, Wang $C L$, Shaio MF. Production of cytokines and platelet activating factor in secondary dengue virus infections. J Infect Dis. 1995; 172(2):604-5. https://doi.org/10.14302/issn.2372-6601.jhor-14-381.

18. Sellahewa KH. Haematological disturbances in dengue Haemorrhagic fever-its pathogenesis and management perspectives. J Hematol Oncol Res. 2015;1(3):15

19. Djamiatun K, Van der Ven AJ, de Groot PG, Faradz SM, Hapsari D, Dolmans WM, Sebastian S, Fijnheer R, de Mast Q. Severe dengue is associated with consumption of von Willebrand factor and its cleaving enzyme ADAMTS-13. PLoS Negl Trop Dis. 2012;6(5):e1628. doi.org/https://doi.org/10.1371/journal.pntd.0001628.

\section{Publisher's Note}

Springer Nature remains neutral with regard to jurisdictional claims in published maps and institutional affiliations.
Ready to submit your research? Choose BMC and benefit from:

- fast, convenient online submission

- thorough peer review by experienced researchers in your field

- rapid publication on acceptance

- support for research data, including large and complex data types

- gold Open Access which fosters wider collaboration and increased citations

- maximum visibility for your research: over $100 \mathrm{M}$ website views per year

At BMC, research is always in progress.

Learn more biomedcentral.com/submissions 